\title{
Receiving Newman: Formalism, minimalism, and their Philosophical Preconditions
}

\author{
Espen Dahl
}

\begin{abstract}
A в STRACT Despite the divide between American formalism and theoreticians of minimalism, Barnett Newman's art received great acclaim from both schools of thought. Attempting to unearth the philosophical preconditions of this strange constellation, this article argues that the closeness between minimalism and formalism is due to their mutual reliance upon phenomenology and ordinary language philosophy. However, their proximity also conveys their distance, since they imply different interpretations and applications of the philosophical schools in question. Such theoretical differences shed light on Newman's paintings: both minimalism and formalism are right in their accounts - yet not exclusively so. What arguably makes up the distinctive fascination of Newman's paintings is their incessant oscillation between empty physicality and powerful meaning.

KEYWORDS Barnett Newman, formalism, minimalism, phenomenology, ordinary language philosophy
\end{abstract}

Barnett Newman's mature paintings, typically consisting of one or more so-called "zips" on a monochromatic background, are extremely simple, yet powerful. The scarce use of artistic means along with the self-contained appearance raise the question as to whether the paintings convey any meaning at all: do Newman's paintings call upon interpretation and convey some kind of meaning, or have they transgressed the line where the concept of meaning itself is no longer apt - as if the picture morphs into a mere object?

Such questions are not new. According to Richard Shiff, critics started dividing into different camps on these central questions already in the 1960s. ${ }^{1}$ On the one hand, there were those who emphasised the act of creation and the existential subject matter of painting, most famously advocated by Harold Rosenberg. Such an understanding was also reflected in many of Newman's own writings, not least in his treatment of the sublime. ${ }^{2}$ On the other hand, the emerging minimalist movement of among others Donald Judd, Robert Morris, and Richard Serra conveyed a new aesthetic sensibility. Their focus on minimal means (shape, colour, composition) and their avoidance of representation and symbolic meaning retroactively influenced the reception of Newman's art. These critics cherished Newman's willingness to let paint be paint, to let matter and form signify nothing beyond their physical presence. In between those two camps we might locate a third one, comprising the formalism of 
Clement Greenberg and Michael Fried. As a critical theory of art, formalism paid special attention to the organisation of the structural elements of art and their particular impact on the aesthetic experience. Its proponents were also among those who defended modernist art against the extended field of art as expressed in minimalism, pop art, and performance. Although Greenberg and Fried agreed with minimalism in emphasising the formal aspects of Newman's art, they sided with more traditional aesthetic approaches in so far as they regarded visual meaning as indispensable. As minor as the difference between minimalism and formalism might seem, it turned on the focal question of the future of modernism.

This essay aims at unearthing the philosophical presuppositions that condition the complex relation between formalism and minimalism. In order to make this relation salient, I will start by discussing, rather briefly, how formalism and minimalism, despite the fierce antagonism of their respective aesthetic orientations, come surprisingly close in their responses to Newman's art (1). I will contend that what establishes their closeness, from a philosophical perspective, is their common indebtedness to phenomenology and ordinary language philosophy; their distance is arguably an outcome of the different interpretations of the two philosophical movements. These interpretations imply different phenomenological accounts of spatial and temporal experience, as well as of the constitution of meaning according to different versions of ordinary language philosophy $(2-3)$. Finally, the disclosure of the philosophical preconditions of formalism and minimalism paves the way for what I take to be a more adequate aesthetic conception of Newman's paintings that moves beyond their oppositions. I propose that the opposition between sheer physicality and expressive meaning should not be regarded as mutually exclusive, but rather as constituting the inherent ambiguity of the paintings (4).

\section{Newman as received by minimalism and formalism}

The centrality of Newman's art is indisputable to both formalists and minimalists. Greenberg repeatedly refers to colour field painters, such as Newman, Rothko, and Still, as the peak of high modernism. Underwriting this perception, Fried argues that "Newman stands alongside Pollock as one of the two most seminal figures of Abstract Expressionism". ${ }^{3}$ But also Donald Judd, representing the minimalist camp, celebrates Newman's achievements, stating that "it's not so rash to say that Newman is the best painter in this country". ${ }^{4}$ Not only does this converging high 
regard for Newman's art make Newman an interesting transitional figure, situated both inside and outside the confines of modernism; it also indicates a strange closeness in the otherwise distinct orientations of formalism and minimalism.

However, the oddity of this closeness can only be appreciated against the background of their more general opposing tendencies. According to Judd, Newman's paintings are simply stripes placed on a canvas, in a certain pattern, with a certain size and with the use of certain colours. "This description," Judd admits, "may have been dry reading but that's what's there."5 Naturally, Judd reads back his own artistic programme into Newman's paintings - or, more precisely, finds his "specific objects" foreshadowed there. It is the overcoming of representation and expressive gestures that is at the heart of minimalism's concern, and in this sense Judd regards Newman as transgressing modernism from within. The reasons for formalists' appreciation of Newman are opposite: they regard Newman as representative of modernist art, representative because he solves the problems that are inherent in modernism.

For Greenberg, modernism is a kind of transcendental critique in Kant's sense; it is both a way of making explicit the conditions of possibility that different disciplines of art presuppose, as well as a self-limitation of each discipline to its area of competence. ${ }^{6}$ This leads to the purification of what belongs exclusively to each media of art - to music, to sculpture, to painting - that is, to the essence of each medium-specific discipline of art. As for painting, Greenberg famously writes that its essence consists of flatness and the delimination of flatness, which implies that "the observance of merely these two norms is enough to create an object which can be experienced as a picture". This view forces him to admit that "a stretched or tacked-up canvas already exists as a picture - though not necessarily as a successful one". 7 As an unintended consequence, such statements leave the door open for minimalism and for minimalism's reading of Newman, for Greenberg seems forced to conclude that, even if not good art, a mere object is the natural end-point of modernism's inherent teleological trajectory. ${ }^{8}$

But it is possible to inherit formalism in another way, and this other way is proposed by Fried and his philosophical ally, Stanley Cavell. In keeping with their understanding, there is essence in art, but this essence is neither timeless nor teleologically fixed, as Greenberg thinks; rather, it is like a convention, i.e. something which gradually changes according to cultural developments as well as being subject to constant tests and challenges by modern art. ${ }^{9}$ There is still one vital point on which Fried 
adheres to Greenberg's position: he still thinks modernist art is irreducibly genre-specific. Although Judd regards minimalist works as a specific group of objects, they are nonetheless, as he puts it, "neither painting nor sculpture".$^{10}$ Of course, such a position flies directly in the face of formalists' fundamental prescription for modernist art as committed to specific media. From this Fried draws the conclusion that " $[\mathrm{w}]$ hat lies between the arts is theater"11, and Fried's "theater" is the emblem of everything that pretends to be or look like modern art, but which fails to live up to its demands. Fried's charge is, of course, that minimalism is theatrical. But is it possible to save Newman from theatre? Greenberg and Fried would undoubtedly believe so, but Judd - if he accepted the term - would have denied it. The interesting thing is that despite these clearly antagonistic positions between formalism's and minimalism's general approaches to art, they still come very close in their reception of Newman's paintings, or more precisely, in their agreement that scale and openness are essential to Newman's achievement.

Starting with the first aspect, everyone recognises that Judd is right in stressing the importance of scale; for it is a historical fact that during the late 1940s, the canvases of many American artists grew in size. For Judd, the importance of scale resides in the unmediated effect with which it confronts the spectator. Newman, along with Pollock and Rothko, did contribute to the discovery of scale and its function in painting, a discovery Judd regards as one of the most important in the twentieth century. ${ }^{12}$ Judd's assessment is, of course, motivated by his commitment to the programme of the evolving minimalist art. For one thing, one of Judd's own reasons for leaving the conventional painting behind and generating three-dimensional objects is to exceed it in "power". For another, the primacy of scale over form and content also points to the primacy of the physical basis of the painting over its pictorial meaning. As Judd puts it: "The painting is nearly an entity, one thing, and not the indefinable sum of a group of entities and references." ${ }^{13}$ For this reason, the simplicity and unity of Newman's paintings draw them close to Judd's specific objects. Formalism also regards scale as internal to the achievement of abstract expressionism; Greenberg, for instance, notes how scale and size assure purity of colours and the intensity of an unlimited room - an intensity not unlike Judd's "power", one might assume. ${ }^{14}$

Newman's paintings are also emphatically open, and what Judd implies by openness is a form freed from traditional conventions. Newman is free from the limits of naturalism and from any kind of representationalism, but Judd also claims that Newman transcends limitations that 
have governed much of abstract painting since Mondrian, namely its dependency upon geometry. Although Newman displays what could be taken as a simple geometrical form - his "zips"- Judd believes that he does not yield to any of the ontological presuppositions for doing so (e.g. what Judd thinks of as Mondrian's Platonism). ${ }^{15}$ In much the same vein, Greenberg agrees that Still, Rothko, and Newman are the first to produce serious abstract pictures, freed from the ties of the past, more specifically, from geometrical abstraction. According to Greenberg, it would be utterly mistaken to read Newman's paintings as responses to geometrical occupations; the employment of simple geometrical figures is rather a freely chosen way to solve the internal problems of the medium of painting. ${ }^{16}$ For Judd, the final and decisive limitation of Newman is that he remains a painter, confining himself to a rectangle hanging on the wall. Since Judd opts for three-dimensional objects, it becomes clear that he disagrees with the more technical meaning of "openness" as defined by Greenberg and Fried. Their sense of openness refers to the abstract colour field which conveys painterly meaning, not by invoking tactile illusions (as architecture and sculpture do), but solely by optical or visual means. Contrary to Judd's conviction, it is precisely Newman's fidelity to the medium of painting that gives rise to formalism's high regard for it. ${ }^{17}$

These overall tendencies draw the minimalist and formalist approaches to Newman closer to each other than one might expect from their dissimilar standpoints. If they agree on Newman to such a degree, why are their perspectives on the significance and purpose of art so deeply divided? Of course, they do advocate different normative opinions of art - but are there other, more philosophical reasons hidden beneath this simultaneous convergence and divergence?

\section{Two interpretations of phenomenology}

One way of answering this question is by interrogating the philosophical presuppositions of minimalism and formalism. Such influential commentators as Rosalind E. Krauss and Hal Foster point out how minimalism conveys a new philosophical reflection on art, both with regard to structures of meaning and perception. This philosophical change is often depicted as a change from idealism - supposedly presupposed in formalism and expressed in abstract expressionism - towards ordinary language philosophy and phenomenology. In both cases, the attention is led away from the ideal and towards the concrete. My claim is that there is some truth in this, but that the change has on the whole been misconceived. It is true that there is a change in theoretical orientation, 
but the change is not a matter of rejecting or embracing phenomenology and ordinary language philosophy. It is, I will argue, a matter of different interpretations of the two strands of philosophy, having to do with different views on each philosophy's relation to the world (time and space), subjectivity and meaning.

Starting with phenomenology, minimalist works force a shift of emphasis, from the more or less hidden intention of the work to the intentionality of the beholder, that is, to the way the beholder perceptually directs him- or herself toward the work. ${ }^{18}$ Minimalism's stripping bare of the aesthetic object invokes an intensified self-reflective awareness in the beholder; with almost nothing engaging the view, the beholder's awareness is thrown back on him- or herself. Such a shift follows the structure of Edmund Husserl's main methodological step, namely the phenomenological reduction: by distancing oneself from one's lived experience - the so-called natural attitude in which one is usually absorbed - one guides the intentional ray away from the intentional object in order to reflect back on how the phenomena manifest themselves in the first place. ${ }^{19}$ In Husserl's view, phenomenological reduction uncovers the constitutive interplay of world, given in time and space, and subjectivity. The phenomenological reduction does not remove, but adds, as it were, a third dimension to the two-dimensionality of our natural attitude. ${ }^{20}$ Art, too, has the power to initiate the reduction; whether confronted by abstraction or literal objects, our habitual preconceptions are radically questioned and thus brought to our attention. Two central conditions for our world relation are indeed how the world is given to us in space and in time. However, minimalism and formalism draw on significantly different accounts of our spatio-temporal perception of the world.

The minimalist works call attention to space by bringing the entire situation into account: the staging, context, position, and horizon are regarded as part of the work. ${ }^{21}$ Since the beholders' bodily awareness of the entire situation is integral to the aesthetic experience, they are no longer regarded as spectators of self-contained works, looking at them from a distance. Moving between, say, the enormous meta-constructions of Richard Serra surely invokes bodily impressions and reactions. How the living body participates in such perceptual processes is elaborated by Maurice Merleau-Ponty in his Phenomenology of Perception, a work that has become almost a standard reference in accounts of minimalism. According to Merleau-Ponty, the spatial dimension is inherently linked to the possible movements and habits of the human body. ${ }^{22}$ Confronted by, or even surrounded by, Serra's objects, we become immediately aware 
of our embodiment as essential to our orientation in space, in a way that resembles the phenomenological reduction to our basic, subjective conditions for perceiving the world.

Time is also an integral factor in the minimalist situation. There is nothing ecstatic about the temporal experience that is enacted in minimalism; it concerns duration as it flows in everyday life. Moving around one of Robert Morris' L-beams, nothing new happens; the anticipations of the hidden parts are harmoniously fulfilled as one inspects the beams from different angles. As in ordinary experience, for the most part temporality contains no surprises, but merely unfolds more of the same. Indeed, as minimalism undertakes a reduction, it manifests an essential homogenous space and time. There are no traces of particularly important places and no fullness of time that stand out; Judd's industrially produced "stacks" suggest that they can progressively go on and on in space and time without anything qualitatively new occurring.

Phenomenology challenges the old dichotomies in idealist philosophy between inner and outer and between subject and object, and so does minimalism. As alluded to above, Foster characterises the theoretical preconditions of abstract expressionism as idealist, and argues that minimalism's new phenomenological orientation effectively undercuts this precondition: "Minimalism thus contradicts the two dominant models of the abstract expressionist, the artist as existential creator (advanced by Harold Rosenberg) and the artist as formal critic (advanced by Greenberg)". ${ }^{23}$ There are indeed differences in the implied philosophy of minimalism and abstract expressionism, and Rosenberg's emphasis on the act of creation and its psychological and existential source does not fit neatly into the phenomenological attention that Judd's objects invoke. ${ }^{24}$ However, it is not fully convincing when Foster claims that the emergence of minimalism entails a radical change from ontology of essence to epistemology of experience in art. As I interpret it, formalism's philosophical preconditions are not far removed from those of minimalism, and particularly not from minimalism's theoretical reliance on phenomenological accounts of human experience. ${ }^{25}$

Fried was actually among the first to apply Merleau-Ponty's phenomenology to art criticism. Fried refers to Merleau-Ponty already in his first review of Anthony Caro's sculptures from 1963, and Merleau-Ponty is frequently referred to in later essays. ${ }^{26}$ Although Greenberg might not directly refer to phenomenological philosophers, this does not invalidate the fact that also his criticism might very well be thought of in phenomenological terms. The appeal to the beholder's experience of the work is 
the final court of appeal for formalist art criticism as it is for phenomenology. Speaking for the whole tradition of formal criticism, from Roger Fry via Greenberg to himself, Fried writes: "All judgment of value starts and ends in experience." ${ }^{27}$

What Caro's painted steel constructions provoke, according to Fried, is essentially our bodily mode of being in the world. Caro has found a way to extend modernist sensibility in sculpture to include our kinaesthetic involvements with things. ${ }^{28}$ This might at first seem puzzling since Fried so strongly attacks minimalism for its manner of making the bodily presence felt. However, as he retrospectively explains, it is not the experience of bodily orientation as such that Fried opposes, "but rather that literalism [i.e. minimalism] theatricalized the body, put it endlessly on stage, made it uncanny or opaque to itself, hollowed it out, deadened its expressiveness, denied its finitude and in a sense its humanness". ${ }^{29}$

Caro's sculptures also challenge the way sculptures are conventionally situated in space. Caro's sculptures impress themselves as bodily experiences - just like minimalist objects are reported to do. Defenders of both formalism and minimalism invoke Merleau-Ponty on this point, but there are significant differences. For Fried, the project Caro shares with architecture is the preoccupation with the fact that we have human bodies and are surrounded by a world. However, Caro's way of exploring that fact is by posing something like a phenomenological reduction: it draws attention to that fact, not by invoking alienating "theatre", as minimalism is charged of doing, but by means of abstraction. According to Fried, Caro's ambitions to make sculpture out of our "primordial involvement with modes of being in the world" can only be realised "if antiliteral - that is, radically abstract - terms for that involvement can be found" ${ }^{30}$ While minimalists are satisfied with the effect the objects cause on the beholder, Fried thinks that Caro's sculptures must be seen as integral and meaningful in another way - as gestures. ${ }^{31}$ The fact that painting, as opposed to sculpture, seeks to free itself from the tactile illusions does not mean that it is cut loose from our incarnated being in the world. Formalism's appeal to opticality, I take it, is another way of exploring one's sense of space by way of abstraction - that is, in abstraction or derivation from (yet without denying its ontological dependence on) other tactile and kinaesthetic involvements with our surroundings. Newman brings this opticality to fruition. ${ }^{32}$

Gestural meaning is the central theme of Merleau-Ponty's investigation of the source of meaning common to spoken language and painting. In "Indirect Language and the Voice of Silence", which Fried explicitly 
draws on, Merleau-Ponty argues that painting and sculpture must be regarded as expressive gestures that respond to the world as perceived. Painting articulates aspects of tacit and bodily perceptions that otherwise will remain unnoticed. According to Merleau-Ponty, every bodily gesture - and in particular, every artistic gesture - cannot help but display meaning. The meaning stems from the organic unity of world and the body, a unity which, in Merleau-Ponty's phrase, condemns us to meaning. ${ }^{33}$ Such expressive meaning is indeed something the minimalists want to avoid - an avoidance that formalists think is tantamount to giving up the burdens of art. Merleau-Ponty claims that not even the geometrical abstraction can escape such meaning: "Now austerity and the obsession with geometrical surfaces and forms ... still have an odor of life, even if it is a shameful or despairing life. Thus the painting always says something". ${ }^{34}$ A spatial location will hence inescapably do more than just reflect a homogeneous space, it will always suggest a human space with its complex topography of value and meaning.

Perhaps the most obvious juncture that highlights the different phenomenological approaches of minimalism and formalism concerns temporality. Fried strongly contrasts the time of minimalist objects with the temporality of modernist works of art. Judd's repetition of identical units suggests some kind of indifferent duration that Fried terms "presentment". ${ }^{35}$ A successful modernist work, on the other hand, claims a kind of "presentness" or "instantaneousness", in which the work reveals itself anew in every moment for the attentive spectator. "We are literalists most of the time", Fried writes, perhaps alluding to how the homogenous time, "presentment", has come to take hold of our everyday perception; and against this he claims that "[p]resentness is grace". ${ }^{36}$ Although Fried later regrets the strong religious connotation of his rhetoric, and although it is an exaggeration to turn his plea for modernism to a dogmatic act of faith or even substitute for religious faith, ${ }^{37}$ it is not totally beside the point to contrast profane, ordinary time with something quite different - something like a sublime moment. Here, Fried is in line with one of the most important phenomenologists, Martin Heidegger, as Heidegger calls attention to the phenomenological impact of ruptures in time - the moments when the levelled everyday is brought to a standstill and we are faced with existence as such. ${ }^{38}$ For Fried, however, such ruptures are not matters of anguish and death, but of the experience of art in the moment it lays claims on the beholder. Clearly, this understanding of art's temporality stands in stark contrast to minimalism's hypostatisation of the endless return of the same. For formalists, the disclosed time and space 
as manifested in e.g. Newman's art are heterogeneous dimensions, with ruptures and hidden depths.

\section{Two interpretations of Wittgenstein}

In Krauss' reading, modern sculpture can only be fully appreciated if we realise how it develops alongside not only phenomenology, but also linguistic philosophy. ${ }^{39}$ In this section I will therefore proceed from the different phenomenological interpretations and discuss different ways of drawing on Ludwig Wittgenstein's ordinary language philosophy.

Not unlike Foster's overall strategy, Krauss argues that the passage from abstract expressionism to minimalism brought a new and more adequate philosophical paradigm to art. Although minimalism avoids traces of human gestures and organic life, Krauss argues that it does not aim at overcoming meaning as such. What minimalism comes to is rather the invocation of a new sense of meaning. The model of meaning that abstract expressionism presupposes is, according to Krauss, that of individuals with private inner lives who seek authentic communication through an outer medium. This theory can be seen at work from their paintings, such as Willem de Kooning's "Door to the River", where the relation between the illusionist space and the privacy of the individual self is arguably at stake. ${ }^{40}$ Just one glance at Judd's serially produced objects is enough to realise that there is no allusion to an interior of which this object is an outer sign. If there is meaning in such works, it is completely exhausted in the exteriority itself. Krauss takes minimalism's appeal to such exteriority to be the artistic conclusion of the later Wittgenstein's so-called private language argument. Wittgenstein is interpreted as denying that meaning could be produced in our private interiorities. Such private constitutions of meaning would only mean that we became locked up in separate universes. The sense of "green", says Krauss, would then name only what you alone sense and would thus have no value in public communication.

This question of language and meaning helps us by analogy to see the positive side of minimalism's endeavor, for in refusing to give the work of art an illusionistic center or interior, minimal artists are simply re-evaluating the logic of a particular source of meaning rather than denying meaning to the aesthetic object altogether. They are asking that meaning be seen as arising from - to continue the analogy with language - a public, rather than a private space. ${ }^{41}$

There is no question that Wittgenstein is challenging a certain picture of meaning, and it is also clear that he wants to shift the emphasis from 
private to public criteria. What is discussed in the vast commentary literature on the private language argument is, however, what becomes of the inner as traditionally conceived. Krauss goes far in interpreting Wittgenstein as eliminating privacy altogether, for in her reading of Serra's art she concludes that we ourselves are nothing but the sum of our visible gestures, which she thinks corresponds with what novelists in France thought at that time: "I do not write. I am written." ${ }^{\text {"2 }}$ In other words, minimalism corresponds with the "death of the author", which is to say, the end of the search for original intentions in works. The public web of symbolic structures is all there is to meaning.

Krauss' reading of Wittgenstein makes him look more or less like a behaviourist equipped with access to linguistic structures: there is nothing except outer behaviour, which lends itself to be read as structures of signs. In this account, the interiority is simply eliminated, reduced to behaviour. However, it is far from clear that this is the only or most coherent reading of Wittgenstein. Just to indicate how problematic such a reading is, let me refer to one of Wittgenstein's dialogues: “Are you not really a behaviorist in disguise? Aren't you at bottom really saying that everything except human behavior is a fiction?' - If I do speak of a fiction, then it is of a grammatical fiction." ${ }^{\prime 3}$

Fried seeks to combine phenomenology's insights into experience with that of Wittgenstein's understanding of language and conventions. Fried's interest in Wittgenstein is in a way opposite to that of Krauss. The reason Fried turns to Wittgenstein's philosophy is that he there finds a philosophy that also strives to defeat theatricality. ${ }^{44}$ Fried must obviously rely on another reading of Wittgenstein than Krauss does. Fried's understanding of Wittgenstein relies heavily on the early works of Cavell. ${ }^{45}$ There are several cross-references between Fried and Cavell from the late 1960 s and early 1970s, and in particular they circle around the notion of "acknowledgement". In Fried's writing, acknowledgement seems to mean more or less "acceptance", with reference to art's frank acceptance of its own physical means and limitations as the conditions of expressive meaning. But the conditions and limitations that are of primary interest to Cavell are not art but the I-you relationship. In this relationship both unity and separation are involved. The notion of acknowledgment first shows up in discussions of the epistemological problem of other minds, a problem to which Wittgenstein's private language argument can be read as a response. ${ }^{46}$

Cavell agrees with Krauss' stress on the public dimension of meaning in his reading of the private language argument. But, Cavell insists, Witt- 
genstein nowhere denies the possibility of a private language, only certain misguided pictures of it. More accurately, the picture Wittgenstein wants to free us from is the private as a secret interiority, unavailable to others but transparent to the self, a picture in which inner meaning must be translated to outer meaning by means of a third, extrinsic feature: the body or language. ${ }^{47}$ To render human expressivity meaningful, Cavell agues, it has to accord with a common orientation in natural reactions and shared linguistic grammar. What gives rise to scepticism towards others' meaning, and more generally to other minds, is that such common meaning can fail: from time to time we experience that we remain strangers to each other, that we disguise our feelings or refrain from communicating. However, Cavell argues that such cases are not matters of inexpressivity, but of deflected modes of expressivity. Human expressivity is indeed complex, but it is also limited, for it is bound to the fragile conditions that our shared grammar provides. Our relation to the other does not rely on proofs, but on acknowledging other's gestures (bodily or linguistic) as expressive of mind.$^{48}$ As an analogue to the human body, Fried thinks that modernist art must acknowledge its physical support as its conditions for its expressivity, as Newman exemplarily does. ${ }^{49}$

As Cavell takes it, the private language argument leads neither to a behaviouristic elimination of an inner realm, nor to a symbolic structuralism in which human meaning is merely a derivate of the system. Human expressions, according to Cavell, imply a subject willing to take responsibility for what one says without fully controlling its meaning. The private language is a depiction of a sceptical, secret wish, namely the wish to secure meaning within an inexpressible interiority, without having to expose ourselves and being responsible for our expressions:

A fantasy of necessary inexpressiveness would solve a simultaneous set of metaphysical problems: it would relieve me of the responsibility for making myself known to others - as though if I were expressive that would mean continuously betraying my experiences, incessantly giving myself away; it would suggest that my responsibility for self-knowledge takes care of itself - as though the fact that others cannot know my (inner) life means that I cannot fail to. ${ }^{50}$

The relief from the burden of expressiveness can either be established by securing a secret interiority, but also by its flip-side - by relying on a flawless and impersonal linguistic system. Both the fantasy of a secret inner world and Krauss' behaviourism merged with structuralism are moved by a sceptical wish to escape the burden of meaning, in Cavell's view. 
From Cavell's (and Fried's) perspective, it seems reasonable to suspect that minimalism's prefabricated boxes, plates, or beams share in this sceptical fantasy. ${ }^{51}$ Even if minimalist objects cannot fully escape meaning, their mode of meaning bears no personal traits; they deliberately put an end to the question of expression and intention - which is the proper question that art raises and demands responses to. This is why, according to Cavell and Fried, pop art and minimalism do not even aspire to raise the serious question of art. Modernism, as both Cavell and Fried think of it, has made art even more fragile than other human utterances, for the burden of modernism means to go on expressing oneself in a time where there are no established criteria for what counts as artistic expression or what its medium demands. Modernism's modes of expression and communication do not rely on established conventions - they do not have anything more to go on than deeply personal styles. ${ }^{52}$

According to Cavell, the relevant question to a meaningful work concerns its intention - not, of course, as if intentions were stored in the private soul of the artist, but as the meaningful dimension of the produced work. To be interested in the work's intentions is to take seriously how art celebrates the breadth and even inescapability of human meaningfulness. Since chance, brute nature, or sheer objecthood do not display intentional meaning, they cannot count as works of art. Someone must be responsible for meaning it: "The artist is responsible for everything that happens in his work - and not just in the sense that it is done, but in the sense that it is meant. It is a terrible responsibility; very few men have the gift and the patience and the singleness to shoulder it." ${ }^{53}$ From this angle, minimalism appears to undo this yoke by appealing to a sense of meaning that is cut loose from human expressiveness, its fragility, and its subjective responsibilities.

Arguably, then, formalism relies on another understanding of Wittgenstein than minimalism does. Where Krauss thinks minimalism cashes in Wittgenstein's turn to the public at the expense of the inner realm, Cavell thinks Wittgenstein supports formalism's stress on meaning as a commitment to personal expressivity: "the first fact of art is that they are meant, meant to be understood." 54

\section{The ambiguous internal movement}

The common points of departure (phenomenology and ordinary language philosophy) and their different interpretations enable us to more clearly understand the complex relation between formalism and minimalism. And given such an understanding, it is now possible to shed 
further light on Newman's art. Both formalism and minimalism regard Newman as exemplary, revealing their programmatic conception of art; this can either mean that one or both are entirely wrong, or that Newman's paintings situate themselves precisely on the transition between high modernism and minimalism. The fact that their respective responses to Newman agree on the paintings' principal dimensions - their acute sense of scale and openness - speaks in favour of such a transitional position. Even if Newman's transitional character has some obvious historical backing, it does not solve the more theoretical question of how, in that case, such a position should be conceived. Shiff's detailed discussion of this issue does not solve the case, nor does it attempt to do so. For on the one hand, there is evidence that Judd captures Newman's phenomenological (in the sense of minimalist) attention to the scale and physicality of his works. Yet, on the other hand, the expressive, even metaphysical dimension is never given up by Newman. Shiff concludes: "If there was phenomenology to Newman's art ('physical properties'), there was also metaphysics ('the spiritual'). Newman himself regarded his art as a mix of phenomenology and metaphysics. ${ }^{\prime 55}$ While formalism never gives in to metaphysical interpretations, its reception at least tries to preserve the expressive dimension in which Newman's spiritual aspirations can be redeemed.

One might perhaps say that both formalists and minimalists have successfully pointed at some aspects of Newman's achievement, but that they at the same time have failed. They have failed not only because their respective accounts remain inadequate, but also because each preferred account excludes the other. While minimalism wants to remove every trace of human expressivity in order to move towards a depersonalised sense of meaning, formalism defends the necessary human expressivity and sees its success in overcoming the medium's objecthood. Although formalists openly acknowledge the presence of physical conditions in modernist painting, the verge between art and objecthood remains absolute. Greenberg articulates the options thus: "[L]ike any other kind of picture, the modernist one still assumes that its identity as a picture shuts out awareness of its identity as an object. Otherwise it becomes, at best, sculpture; at worst, a mere object." ${ }^{56}$ From both sides - both minimalism and formalism - the antithetical logic is upheld: either painting or object.

The third option I want to propose is to displace the conflict: from a struggle about the adequate reception of the paintings, to a struggle that goes on within the paintings. For is it not precisely the unresolved conflict that constitutes the intriguing dimension of Newman's painting? 
Is it not its closeness to a simple object along with its powerful expressivity that constitutes its fascination? In objecting to formalism on this point, Jay M. Bernstein suggests that minimalism should not so much be regarded as something external to modernist painting, but rather like a permanent inner tendency. In drawing on Cavell's understanding of scepticism, Bernstein regards modernism as bargaining with objecthood in a way similar to Wittgenstein's bargaining with scepticism: "Every modernist work raises the issue of fraudulence and trust, which is to say that every modernist work of art raises an equivalent of the problem of other minds: what is it for a material display to be a display of human meaning, that is, the display of a person?"57 Modernist art's fate is to expose itself to the threat of the nihilism inherent in minimalism, and not to excommunicate it, as Fried tends to. There is no guarantee that meaning survives this threat. Newman's paintings can convey meaning, but nothing prevents them from sinking into mere objects hanging on the wall.

A similar point can be made with regard to the two interpretations of phenomenology we have discussed. For the two interpretations implied in minimalism and formalism are not necessarily mutually exclusive. They can rather be regarded as two rivalling attitudes within an overall phenomenological enterprise. At least Husserl opens up for two such attitudes in which the spatio-temporal world is sketched out differently, one called naturalistic attitude, the other personalistic attitude. In the naturalistic attitude - roughly speaking the attitude of the natural scientist - the world is perceived of as matter, as mere things stripped of any value or practical use. It is the world of things causally related within homogenous space and time. It would not be correct to say that the things, approached from the naturalistic attitude, are senseless, but they are certainly not bearers of any human expressivity. ${ }^{58}$ As I see it, the naturalistic attitude comes close to the one that minimalist works demand. However, we are able to change our attitude, and for formalism any work of art worthy of the name demands another attitude - something like a personalistic attitude. According to this attitude, the disclosed world is here regarded as already meaningful, as the field of practice, communication, and value. The world is encountered as the field in which we unfold our lives. ${ }^{59}$ In the personalistic attitude, nothing can be stripped bare of its meaning; everything is already "condemned to meaning", as MerleauPonty (and later Cavell) will have it. ${ }^{60}$ Although both these attitudes are part of the phenomenological repertoire and hence internally related, it might be possible to read Newman's painting as enacting a particular 
tension or strife between them. The typical effect of his works is to induce the oscillation between them. ${ }^{61}$

Let me take "Abraham" as an example. At first sight it offers a largescaled black canvas. The almost monochrome appearance makes the whole picture move towards emptiness. The initial impression is disappointing because the painting does not seem to have anything to convey. Its physicality - its rectangular shape, the canvas, the black paint - is made visible because it seems to be the only thing that is there: a mere object. However, one gradually becomes aware that something is going on in the painting after all. From the dark green-black field emerges a broad stripe in black. The stripe is not completely symmetrically arranged, as the orange zip in Newman's "Onement" is, but is rather placed slightly to the left side. This intrigues the perceptual process and makes the play between the field and the zip into a fascinating oscillation between background and "figure". The questions arise: What has primacy and what must fade? What insists on being the figure and what must constitute the background $?^{62}$ There is some meaning to this, as if the zips, their contours and interplay of dark colours, make up what Fried calls a meaningful syntax or gestures of their own. These gestures reflect meaning absorbed from the world outside the painting, transformed by abstraction. This expression opens up a world. This is not the ordinary world as we already know it, but a world distant enough to open our sensibility anew, and intimate enough to refer back to the primordial, embodied world relation from which it remains anchored. And yet, the means are so scarce that we are never certain that the painting will not sink back into a mere object again. This threat is internal to the works themselves.

Central to the notion of the sublime is a wavering between the fascinating and the threatening. If the ambiguous movement between objecthood and expressivity can, in an analogous way, be termed sublime, then we have found a way to make sense of the spiritual dimension that Newman saw as essential to his art. ${ }^{63}$ But even more important, this is achieved along a path that does not deny the importance of both formalists' and minimalists' respective accounts of Newman. What is seriously questioned, however, is each party's dogmatic, antithetical either-or claim on his art as such. For, as I take it, it is precisely by transporting the external conflict between formalism and minimalism into Newman's works themselves that we gain a more adequate conception of them. 


\section{Notes}

1. Richard Shiff, "Whiteout: The Not-Influence Newman Effect", in Barnett Newman (Philadelphia: Philadelphia Museum of Art, 2003), 84.

2. Barnett Newman, "The Sublime is Now", in Looking at Barnett Newman, ed. J. Lewison (London: August, 2002), 110-13.

3. Michael Fried, "Three American Painters: Noland, Olitski, Stella", in Art and Objecthood: Essays and Reviews (Chicago: The University of Chicago Press, 1998), 234.

4. Donald Judd, "Barnett Newman", in Complete Writings 1959-1975 (New York: The Press of the Nova Scotia College of Art and Design, 2005), 200.

5. Ibid., 201.

6. Clement Greenberg, "Modernist Painting”, in Collected Essays and Criticism, Vol. 4 (Chicago: University of Chicago Press, 1992), 85.

7. Greenberg, "After Abstract Expressionism", in Collected Essays and Criticism, 131-32.

8. Cf. Thierry de Duve, Kant after Duchamp (Cambridge, Mass.: MIT Press, 1996), 222-23, 231. Fried criticises Greenberg for having no truer followers than minimalist artists. Fried, "An Introduction to My Art Criticism", in Art and Objecthood, 36.

9. For an account of the two understandings of art after Greenberg, see Diarmuid Costello, 'On the Very Idea of a 'Specific' Medium: Michael Fried and Stanley Cavell on Painting and Photography as Arts", Critical Inquiry 34 (2008): 286-87.

10. Judd, "Specific Objects", in Complete Writings 1959-1975, 181.

11. Fried, "Art and Objecthood", in Art and Objecthood, 164.

12. Ibid., 202.

13. Judd, "Specific Objects", 182.

14. Greenberg, "American-type' Painting”, in Art and Culture: Critical Essays (Boston: Beacon Press, 1989), 219, 227.

15. Judd, "Barnett Newman", 202.

16. Greenberg, "'American-type' Painting", 226.

17. Fried, "An Introduction to My Art Criticism", in Art and Objecthood, 19-22. 18. Hal Foster, The Return of the Real (Cambridge, Mass.: MIT Press, 1996), 50. 19. For Husserl's different accounts of his phenomenological reduction, see Iso Kern, "Die drei Wege zur transzendental-phänomenologischen Reduktion in der Philosophie Husserls", Tijdschrift voor Filosofie 24 (1962): 303-49.

20. Edmund Husserl, Die Krisis der europäischen Wissenschaften und die transzendentale Phänomenologie: Eine Einleitung in die phänomenologische Philosophie. Husserliana VI. Ed. W. Biemel (The Hague: Martinus Nijhoff, 1954), 126.

21. Robert Morris, "Notes on Sculpture", in Minimal Art: A Critical Reader, ed. 
G. Battcock ( Berkeley: University of California Press, 1995), 231. Foster, The Return of the Real, 38.

22. Maurice Merleau-Ponty, Phenomenology of Perception (London: Routledge, 1962), 98-102.

23. Foster, The Return of the Real, 40.

24. Cf. Harold Rosenberg, "The American Action Painters", in Reading Abstract Expressionism. Context and Critique, ed. E. G. Landau (New Haven: Yale University Press, 2005), 190-91.

25. Foster, Return of the Real, 40.

26. Cf. his retrospective comments on Merleau-Ponty's strong impact on his theoretical stand in "An Introduction to My Art Criticism", 28-30.

27. Fried, "Three American Painters", 215.

28. Fried, "Two Sculptures by Anthony Caro", in Art and Objecthood, 181.

29. Fried, "An Introduction to My Art Criticism", 42. These formulations are perhaps inspired by Stanley Cavell's formulations of minimalism. Cf. The World Viewed (Cambridge, Mass.: Harvard University Press, 1979), 117.

30. Fried, "Two Sculptures of Anthony Caro", 181.

31. Fried, "Anthony Caro", in Art and Objecthood, 275.

32. Fried, "Three American Painters", 231-33.

33. Merleau-Ponty, Phenomenology of Perception, xix.

34. Merleau-Ponty, "Indirect Language and the Voice of Silence", in Signs (Evanston, Ill.: Northwestern University Press, 1964), 56.

35. Fried, "Art and Objecthood", 166.

36. Ibid., 167.

37. Cf. Foster, Return of the Real, 52.

38. Martin Heidegger, Sein und Zeit, (Tübingen: Niemeyer Verlag, 1993), 252-55.

39. Rosalind E. Krauss, Passages in Modern Sculpture (Cambridge, Mass.: MIT

Press 1977), 4.

40. Ibid., 256-58.

41. Ibid., 262.

42. Ibid., 270.

43. Ludwig Wittgenstein, Philosophical Investigation (London: Blackwell, 2001), $\int 307$.

44. Fried, "Two Sculptures by Anthony Caro", 181.

45. Fried, "An Introduction to My Art Criticism", 10.

46. Cavell, "Knowing and Acknowledging", in Must We Mean What We Say? (Cambridge: Cambridge University Press, 1976), 258-66.

47. Cavell, The Claim of Reason: Wittgenstein, Skepticism, Morality and Tragedy (Oxford: Oxford University Press 1979), 344.

48. Ibid., 341, 368. 
49. Fried, "Shape as Form", 88.

50. Cavell, The Claim of Reason, 351.

51. For Fried's invocation of scepticism and doubt, see "An Introduction to My Art Criticism", 47.

52. Cavell, Must We Mean What We Say?, xxii.

53. Cavell, "A Matter of Meaning It", in Must We Mean What We Say?, 237.

54. Ibid., 227-28.

55. Shiff, "Whiteout: The Not-Influence Newman Effect", 101.

56. Greenberg, "Picasso at Seventy-Five", Art and Culture, 67.

57. Jay M. Bernstein, Against Voluptuous Bodies: Late Modernism and the Meaning of Painting (Stanford: Stanford University Press, 2006), 101.

58. Husserl, Ideen zu einer reinen Phänomenologie und phänomenologischen Philosophie. Zweites Buch. Phänomenologische Untersuchungen zur Konstitution. Husserliana VI. Ed. W. Biemel (The Hague: Martinus Nijhoff, 1952), 25-27.

59. Ibid., 185-90.

6o. Merleau-Ponty, Phenomenology of Perception, xix. Cavell, The Claim of Reason, 351.

61. Hans Ulrich Gumbrecht has recently made a similar reading of the "strife" between earth and world in Heidegger's aesthetics. Production of Presences: What Meaning Cannot Convey (Stanford: Stanford University Press, 2004), 70.

62. Cf. Yves-Alain Bois, "Perceiving Newman", in Painting as Model (Cambridge, Mass.: MIT Press, 1990), 203.

63. Newman, "The Sublime Is Now", 113. For a reading of the sublime in Newman along the lines indicated above, see Espen Dahl, "Sublimt og hellig. Om det hverdagsliges gjenkomst og estetisk erfaring", in Norsk Filosofisk Tidsskrift 42 (2007): 225-29. 